\title{
Research Paper: The Effect of Three Methods of Kin- esthetic Imagery, Active, and Combined Exercises on Electromyographic Pattern of Hip Hyperextension and the Muscle Strength of Gluteus Maximus and Abdominal in Women With Lumbar Hyperlordosis
}

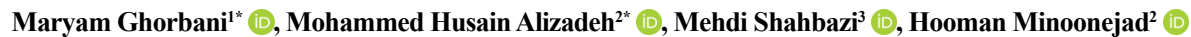 \\ 1. Department of Sports Injury and Corrective Exercise, Pardis Alborz of University of Tehran, Tehran, Iran. \\ 2. Department of Sports Injury and Corrective Exercise, Faculty of Physical Education, University of Tehran, Tehran, Iran. \\ 3. Department of Motor Behavior, Faculty of Physical Education, University of Tehran, Tehran, Iran.
}

\begin{tabular}{|c|c|}
\hline $\begin{array}{l}\text { Use your device to scan } \\
\text { and read the article online } \\
\end{array}$ & $\begin{array}{l}\text { citation Ghorbani M, Alizadeh MH, Shahbazi M, Minoonejad H. The Effect of Three Methods of Kinesthetic Imagery, Active, } \\
\text { and Combined Exercises on Electromyographic Pattern of Hip Hyperextension and the Muscle Strength of Gluteus Maximus and Ab- } \\
\text { dominal in Women With Lumbar Hyperlordosis. Physical Treatments. 2021; 11(3):145-156. http://dx.doi.org/10.32598/ptj.11.3.36.3 } \\
\text { doi http://dx.doi.org/10.32598/ptj.11.3.36.3 }\end{array}$ \\
\hline
\end{tabular}

(c) (i) (5)

Article info:

Received: 27 Jun 2020

Accepted: 14 Feb 2021

Available Online: $01 \mathrm{Jul} 2021$

\section{A B S T RA C T}

Purpose: Mental exercise uses the same neuronal pathways involved in physical exercise to modify the pattern and function without stress caused by physical exercise. This study investigates the effect of kinesthetic imagery, active, and combined exercises (imagery and active) on the hip hyperextension and the power of selected lumbopelvic muscles in women suffering from lumbar hyperlordosis.

Methods: In this quasi-experimental study, 36 women with lumbar hyperlordosis (age range: 30-40 years, non-athlete and without injury and surgery in the lumbar region) were selected and divided into three groups. The groups practiced three sessions per week for six weeks. We assessed the lumbar lordosis by a flexible ruler and the electromyographic (EMG) activity of the lumbopelvic muscles during hip hyperextension in the prone position by surface electromyogram. We also measured the power of the gluteus maximus using a dynamometer during hip hyperextension and the abdomina muscles using a goniometer during the double leg lowering test. All of the measurements were done before and after the intervention. The normality of the data was checked by The Shapiro-Wilk test, and the obtained data were analyzed by repeated-measures ANOVA test at the significant level of 0.05 .

Results: The variables of lumbar lordosis were significantly reduced in the active and combined groups in the post-test compared to the pre-test, and the strength of gluteus and abdominal muscles in the active and combined groups in the post-test significantly increased compared to the pre-test. However, the lumbar lordosis and strength of gluteus and abdominal muscles in the post-test were not significantly changed compared to the pre-test. Gluteus maximus and abdominis transverse muscle activity rates in the combined group increased significantly in the post-test compared to the pre-test, and gluteus maximus muscle activity rate in the active group increased significantly in the post-test compared to the pre-test. Gluteus maximus muscle activity in the imagery group increased significantly in the post-test compared to the pre-test. The activity of lumbar erector spinae and rectus femoris muscles decreased significantly in the active and combined groups in the post-test compared to the pre-test. However, the activity of the rectus femoris muscle decreased significantly in the image group in the post-test compared to the pre-test $(\mathrm{P}<0.05)$. The results showed a significant difference between the three methods of kinesthetic imagery, active, and combined $(\mathrm{P}=0.001)$. There was a significant difference between the method of the imagery exercise and the active and combined exercise methods but no significant difference between methods of the active and combined exercise.

Conclusion: Imagery exercises effectively modified the EMG of some lumbopelvic muscles (gluteus maximus and rectus femoris muscles). However, it had no significant effect on the strength and degree of lumbar lordosis. The combined exercise was as effective as active exercise in modifying the EMG activity of the lumbopelvic muscles and the strength of the abdominal and gluteus maximus muscles.
Keywords:

Lumbar hyperlordosis, Mental training,

Electromyography,

Lumbopelvic muscles

* Corresponding Author:

Mohammed Husain Alizadeh, PhD.

Address: Department of Sports Injury and Corrective Exercise, Faculty of Physical Education, University of Tehran, Tehran, Iran

Phone: +98 (912) 8092567

E-mail:maryamghorbani@ut.ac.ir 


\section{Highlights}

- Effect of mental imagery exercises on women's movement pattern.

- Mental exercises alone do not change the movement pattern.

- Mental exercises in conjunction with physical exercises cause lasting changes.

\section{Plain Language Summary}

The effect of mental imagery exercises on women's movement pattern was investigated. Therefore, in addition to physical exercises, mental exercises were also used. The results of this study showed that mental exercises alone do not change the movement pattern. But if mental exercises are used in conjunction with physical exercises, it will cause lasting changes in women's movement pattern.

\section{Introduction}

he repeated movement and sustained posture would alter muscle tissue properties [1] so that the musculoskeletal system cannot provide the necessary support for optimal movement with stability [2]. If the stress and strain to different body structures extend beyond tissue tolerance, it can result in pathology [1]. Therefore, motor pattern abnormalities can be a vital factor in musculoskeletal disorders [3, 4]. In this regard, Janda stated that the regular muscle activation pattern during hip extension in the prone position is respectively gluteus maximus followed by hamstring and spinae erectors [2]. The disruption of this natural pattern causes mechanical and compressive stresses on the lumbar spine [2].

One of the most common patterns of disorder seen clinically during the prone hip extension test is an excessive delay in applying the gluteus maximus [1]. In these cases, hip extension is caused by the activity of hamstring muscles, which results in anterior pelvic tilt and lumbar hyperlordosis to compensate $[5,6]$. Therefore, in the lower cross syndrome, the agonist and antagonist balance in the lumbopelvic muscles is disturbed. In this syndrome, erector spinae muscle stiffness is associated with iliopsoas and rectus femoris muscle stiffness and deep abdominal muscles weakness with gluteus maximus muscle weakness [2]. This pattern of muscle imbalance increases lumbopelvic mobility [7], and particularly in activities such as gait, the stability of the pelvis is reduced and thus impedes the body's mechanical efficiency [6]. That is why is used in examining movement patterns, activity levels or sequences, and the order in which muscles are activated as a criterion for examining movement patterns [2, 3]. If the lumbopelvic muscles function normally, they sufficiently stabilize and prevent excessive lumbar curvature and consequently create a normal movement pattern in the lumbopelvic area $[4,5]$

Oh et al. (2007) investigated the effect of inward abdominal maneuvering on erector spinae and hip Electromyographic (EMG) activity and anterior pelvic tilt angle during hip extension in the prone position. Their results showed that inward abdominal maneuvering during hip extension caused a significant decrease in the activity of erector spinae muscle and a significant increase in the activity of the internal hamstring and gluteus maximus [6]. Also, Park et al. (2011) examined the effect of inward abdominal maneuvering on muscle activity and pelvic movement during knee flexion in patients with lumbar extension rotation syndrome [7]. The results showed that the erector spinae muscle activity of the left and right was significantly reduced during the abdominal maneuver. The internal and external hamstring EMG activity was significantly increased. The pelvic tilt, knee flexion, and pain during abdominal maneuver decreased in the prone position during knee flexion. These studies show that by increasing abdominal activity, pelvic tilt is reduced [7, 8].

Since the muscles reflect the function of the Central Nervous System (CNS), any dysfunction of the CNS and the sensory-motor system exhibit adaptive and compensatory manifestations in the motor system $[2$ $4,5]$. Research findings have also shown that physical exercise is an effective intervention to correct imbalances and muscle function. However, the use of mental training methods that increase cerebral cortex activity and attention [9] and thus provide better cognition has 
not been sufficiently addressed. It seems that in mental practice, more repetition can be achieved with less time and its results are similar to physical exercise [9-12]. In this regard, Lebon et al. (2011) examined the increase in muscle activation following the intervention of mental imagery exercise during anterior cruciate ligament rehabilitation. The findings showed that imagery exercises increased muscle activation [13]. Christakou et al. (2007) used mental imagery exercises along with physiotherapy for ankle rehabilitation [14]. Although the researchers used mental intervention to help subjects, the results showed no significant changes in pain, swelling, and range of motion in athletes [15]. Also, Hoyek et al. examined the effect of mental imagery on functional rehabilitation in the syndrome of impingement shoulder. Their results showed that mental imagery exercises increased joint mobility [15].

Findings from these studies suggest that mental exercise along with physical exercise can be used to modify muscle activity patterns [1]. Nevertheless, mental imagery exercises as an effective intervention in correcting motor patterns and musculoskeletal disorders functionality require further studies. The present study aimed to compare the efficacy of active, imagery, and combined exercises on the movement configuration of hip hyperextension and power of gluteus and abdominal muscles in women with lumbar hyperlordosis.

\section{Materials and Methods}

This study is quasi-experimental. To prevent alternative explanations for the observed differences, we selected all subjects from a single cohort (non-athlete women with no history of injury and age range of 30-40 years) [16]. The screening was first performed using an observational evaluation of the sagittal plane. The lumbar lordosis angle was measured using a flexible ruler. Women whose lordosis angle was more than $45^{\circ}$ [17] were included in the study after completing the motion imagery questionnaire; those who achieved the quota [18] were placed in the group of kinesthetic imagery and combined exercises (active and imagery), and the rest in the active exercise group. Also, to avoid spreading the effects of the intervention from one group to another, it was tried to separate the exercise groups as much as possible and each group's training time different from the other training group so that they would neither meet nor be aware of each other's work [16].

The number of samples was calculated using the $G$ Power software with the repeated measures analysis of variance within and between interactions, the effect size of 0.3 (moderate effect size), the number of groups of 3 , the measurement number of 2 , at the significant level of 0.05 and statistical power of 0.85 . Finally, the total number of 36 subjects (12 subjects in each group) was estimated (active exercise group: 12, kinesthetic imagery exercise group: 12, and combined exercises group: 12). The subjects signed a written consent and entered the study.

A flexible ruler, which has been described as validity (0.88) and reliability (0.82) tools for measure lumbar lordosis, was used to measure lumbar lordosis degree [19]. The spinal process of the T12 was used as the starting point of the arch, and S2 as the endpoint [17]. The ruler was then placed on the desired points, and the points were marked on the ruler. The ruler was applied to the paper without any changes, and the curvature formed on the ruler was drawn by a pencil on the paper, and after removing the ruler from the paper, two distinct points were connected to the straight line and draw a straight line on the deepest part of the perpendicular arc and calculate the lumbar arch size using the 4Arctg H/L2 formula [17, 19].

The strength of a gluteus maximus muscle was measured with a dynamometer. The tester would take a prone position on the bed, then bent the knee 90 degrees, and the leather interface is attached to the middle of the thigh. In this case, the subject is asked to apply maximum force to the leather interface. Each subject repeats this test twice with a one-minute interval, and the bestobtained number was considered the maximum isometric strength of the gluteus maximus muscle [17, 20-22].

Abdominal muscle strength was measured using the double leg-lowering test (DLLT) [23]. All measurements were completed by a team of 2 examiners. Subjects wore shorts and removed their shoes to avoid additional external loads. The examiners explained the testing procedure to the subjects, who then were allowed to practice the procedure only once to demonstrate their understanding of the DLLT. When performing the test, each subject lay supine on a wooden table with a 1-cm-thick felt pad with the arms folded across the chest. Two trials were performed with a 1-minute rest between trials. The test began with an examiner helping the subject place her legs in a vertical position with the knees extended to the terminal range as allowed by the flexibility of the hamstrings. Each subject was instructed to keep the pelvis posteriorly rotated, so the lumbar spine was held firm to the table, while slowly lowering the legs to a horizontal position. Examiner 1 monitored the position of the low back from the subject's right side by placing fingers between the low back (L4-5 area) and the table. Examiner 1 verbally signaled Examiner 2 when the subject's back 
began to lift from the monitoring fingers; this represented the end of the test. Examiner 2 recorded the subject's performance with the goniometer. The goniometer was placed on the greater femoral trochanter; then one axis of the goniometer was placed along the long axis of the femur and the other along the trunk. The axis of the goniometer remained parallel to the long axis of the femur while the test was being done. At the signal to end the test, a stop to measure with goniometer occurred [17, 20, 21].

The EMG of transverse abdominal, hip extensors, lumbar extensors, and hip flexor muscles was measured using surface electromyography in the prone position [3]. The individual was asked to perform hip hyperextension in the prone position. To record the electrical activity of the muscles, we used a 16-channel electromyogram (ME model from Flanders and dipole electrodes). In the present study, 4 channels were used for muscle examination. Also, superficial disposable electrodes and FRG rectangular electromyographic (SKINTACT, made in Austria) were used. Electromyographic data were collected at a sampling rate of $1000 \mathrm{~Hz} / \mathrm{s}$. These signals were initially pre-amplified ten times and filtered in the band-pass filter between 20 and $500 \mathrm{~Hz}$. The distance between the electrodes was $2 \mathrm{~cm}$, and the electrodes were positioned on the midline of the muscles according to SENIAM instructions, and then the electrodes were connected to the target points: gluteus maximus muscle, 1.2 distance of $\mathrm{S} 2$ to the greater trochanter; lumbar erector spine muscle, $3 \mathrm{~cm}$ apart of L3 lumbar; transverse abdominis muscle, $2 \mathrm{~cm}$ distal to the upper anterior superior iliac spine to downward and inward and rectus femoris muscle, 1.2 distance of anterior superior iliac spine to under patella (Appendix 1). Electromyographic parameters were recorded with a computer. A metronome controlled the movement speed, and data analysis was performed using the RMS algorithm (Root Mean Square) and megavine software (Mega Electronics, Finland). The EMG of hip hyperextension was recorded for $6 \mathrm{~s}$, and then $1.5 \mathrm{~s}$ from the beginning and the end of this period was eliminated.

The maximum voluntary contraction method was used to normalize the electromyographic data, with each muscle being tested three times the maximal voluntary contraction, and the electromyographic activity of the muscles in $6 \mathrm{~s}$ was recorded. To process the information, 1.5 $\mathrm{s}$ of the first and last part of this time were deleted, and 3 $\mathrm{s}$ in the middle was selected. The maximum value of the three measurements was used for analysis. Finally, the electromyographic activity of each muscle during hyperextension of the femur was divided over the maximum voluntary contraction of the same muscle to normalize the numbers. Then, they were presented as a percentage of maximal voluntary contraction $[3,4]$.
Sahrmann exercises were used for the active exercise group [1]. Active exercises were performed three 60-75 min sessions per week for 6 weeks, including 5 min of warm-up, the main training program for 45 to $60 \mathrm{~min}$, and cool down for $5 \mathrm{~min}$ (Appendix 2). The group of kinesthetic imagery exercises performed the same Sahrmann exercise to form mentally kinesthetic imagery, including the sense of motion, power, or effort during imagery. The imagery exercise was performed three 60$75 \mathrm{~min}$ sessions per week for six weeks, including $5 \mathrm{~min}$ of warm-up, kinesthetic imagery program for 45 to 60 $\mathrm{min}$, and cool down for $5 \mathrm{~min}$. The combined exercise group (imagery and active) was carried out by blocking active exercises and kinesthetic imagery for this purpose, which initially performed the exercises in an active manner after a mental manner, then the process repeated until the end of the exercise (half the exercise as active and half of the exercise as mentally).

The combined exercise was performed three 60-75 min sessions per week for six weeks, including 5 min of warmup, the main exercise program for 45 to $60 \mathrm{~min}$, and cool down for $5 \mathrm{~min}$. Exercises from one set with six replications in the first session began and increased to three sets with eight replications in the last session. All exercises were designed by observing the principle of gradual overload in the number of iterations (from one set with 6 replications, to 3 sets of 8 repetitions, 24 times repeated in the sixth week) and the maintenance period of each movement during the 6 weeks (of the 6 s maintenance of contraction began to $10 \mathrm{~s}$ in the sixth week). The duration of exercise in all three groups was equal (Appendix 2).

All obtained information is presented in average and standard deviation. The obtained data were analyzed using a repeated measure ANOVA test. Before this test, $M$ Box and Mauchly tests were used for the prediction of the assumptions. After the fitting of the data, we investigated the normal distribution of errors. Since the M Box test was insignificant for any research variables, the homogenous condition of the variance matrix was observed correctly. Also, no significant lack of variables in Leven's test indicates the equality of between-group variance, observance, and variance of error-dependent variables in all groups. Finally, the Mauchly test showed that the test was not significant for any variable, so the assumption of the equality of variance in the subjects was observed. The assumption results of the normal distribution of errors were $\mathrm{P} \geq 0.05$, indicating the normal distribution of the error. The significance level was considered 0.05 for all calculations. We also performed a Bonferroni post hoc test to compare a couple of groups. All statistical calculations were performed in SPSS v. 24. 


\section{Results}

Table 1 presents the general characteristics of the subjects by the group. Considering the stage effect in Table 2, there is a significant difference between exercise groups in the pre-test and post-test on the variables of lumbar lordosis degree, electromyographic activity of gluteus maximus, lumbar erector spinae, transverse abdominis, and rectus femoris muscles, and strength of gluteus and abdominal. In other words, there was a significant difference between the pre-test and post-test scores of these groups. Also, the interaction of group-time and group on the variables of lumbar lordosis degree and strength of abdominal muscles showed a significant difference between the exercise groups. A Bonferroni post hoc test was also used to compare the groups in the pre-test and post-test stages between the exercise groups (Tables 3, 4 and 5).

\section{Discussion}

This study investigated the effect of kinesthetic imagery, active, and combined exercises on the electromyographic pattern of hip hyperextension and the power of gluteus maximus and abdominal muscles in women with lumbar hyperlordosis. In lower cross syndrome, the pattern of movement changes due to stiffness and shortness of flexor hip muscles, erector spinae muscles, and weakness of abdominal muscles and gluteus muscles. These muscle imbalances have detrimental effects on the static and dynamic state of the body, especially when walking. This syndrome causes anterior pelvic tilt and increased lumbar lordosis, and slight flexion of the hip joints [1-3]. It alters the transfer of forces in the lumbar and pelvic areas [1], so correcting lumbar hyperlordosis functional abnormalities is necessary.

One of the study's objectives was to investigate the effect of mental imagery exercises on the EMG activity of the muscles of the transverse abdominis, gluteus maximus, and rectus femoris. The results showed that imag- ery exercise increased gluteus maximus activity and reduced rectus femoris muscle activity. In mental imagery, movement is activated by the brain structures that are involved in cognitive control and motor planning; in other words, all cognitive stages of motion control including projection, planning, and readiness of motion are similar to real moves $[11,12]$. In the executive phase the movement is controlled, but the same neural pathway that is activated in active activity results in increased activity of motor units [12], and the activity of the gluteus maximus is increased. Conversely, the activity of the opposite muscle, the rectus femoris, is reduced. Also, increasing the EMG activity following imagery exercises may be related to the activation of the central nervous system.

Based on equivalence and functional equality between mental imagery and motor activity and also, because mental imagery reorganizes the cortex of the same physical exercise that is followed by an increase in the cortex output signals, the muscle tends to increase the level of higher surface activation $[11,12]$. Also, Levan et al. investigated the increase in the activation of muscles following mental imagery during the rehabilitation of the anterior cruciate ligament. Their findings showed that mental imagery increased the muscle tone but decreased the pain [13]. Mental imagery exercises did not affect the transverse abdominis muscle probably because it is deep and needs more intense and longer training to change its activity. Also, because the exercises did not affect the activity rate of the transverse abdominis muscle, so it could not reduce the activity rate of the lumbar erector spinae.

The other objective of the present study was to investigate the effect of active corrective exercises on the EMG activity of transverse abdominis, gluteus maximus, erector spinae, and rectus femoris muscles. And the achieved results are consistent with the results of Oh et al. (2007) and Park et al. (2011) and showed that corrective exercises increased the EMG activity of gluteus maximus and reduced the activity of the EMG of erector

Table 1. General characteristics of the study subjects

\begin{tabular}{|c|c|c|c|c|c|c|}
\hline \multirow{2}{*}{ Groups } & \multicolumn{5}{|c|}{ Mean \pm SD } & \multirow{2}{*}{$\mathbf{P}$} \\
\hline & Age (y) & $\mathbf{P}$ & Height (cm) & $\mathbf{P}$ & Weight (kg) & \\
\hline Active exercise & $34.06 \pm 3.15$ & & $160.60 \pm 14.21$ & & $65.73 \pm 16.06$ & \\
\hline Imagery exercise & $34.27 \pm 4.17$ & 0.93 & $159.54 \pm 10.62$ & 0.87 & $63.52 \pm 15.93$ & 0.81 \\
\hline Combined exercise & $35.08 \pm 4.06$ & & $161.32 \pm 13.08$ & & $22.81 \pm 64.34$ & \\
\hline
\end{tabular}

One-way ANOVA test was used to investigate intergroup differences in age, height, and weight.

$P \geq 0.05$ indicates no significant difference between groups. 
Table 2. Repeated measures analysis of variance for comparison of pre-test and post-test on the variables

\begin{tabular}{|c|c|c|c|c|c|c|}
\hline Variables & Source & Sum of Squares & df & Mean Square & $\mathbf{P}$ & Partial Eta Squared \\
\hline \multirow{5}{*}{ Lordosis degree } & Time & 606.391 & 1 & 606.391 & 0.001 & 0.883 \\
\hline & Groups $\times$ Time & 114.384 & 2 & 57.192 & 0.001 & 0.586 \\
\hline & Error & 80.725 & 29 & 2.784 & - & - \\
\hline & Groups & 103.084 & 2 & 51.542 & 0.013 & 0.260 \\
\hline & Error & 293.525 & 29 & 10.122 & - & - \\
\hline \multirow{5}{*}{$\begin{array}{l}\text { Activity of the } \\
\text { gluteus maximus }\end{array}$} & Time & 218.116 & 1 & 218.116 & 0.001 & 0.414 \\
\hline & Groups $\times$ time & 5.314 & 2 & 2.657 & 0.781 & 0.17 \\
\hline & Error & 309.039 & 29 & 10.657 & - & - \\
\hline & Groups & 14.331 & 2 & 7.166 & 0.925 & 0.005 \\
\hline & Error & 2668.887 & 29 & 92.031 & - & - \\
\hline \multirow{5}{*}{$\begin{array}{l}\text { Activity of the } \\
\text { erector spinae }\end{array}$} & Time & 1001.710 & 1 & 1001.710 & 0.001 & 0.395 \\
\hline & Groups $\times$ Time & 30.372 & 2 & 15.186 & 0.753 & 0.019 \\
\hline & Error & 1535.078 & 29 & 52.934 & - & - \\
\hline & Groups & 43.184 & 2 & 21.592 & 0.827 & 0.013 \\
\hline & Error & 3276.082 & 29 & 112.968 & - & - \\
\hline \multirow{5}{*}{$\begin{array}{l}\text { Activity of the } \\
\text { transverse ab- } \\
\text { dominis }\end{array}$} & Time & 86.578 & 1 & 86.578 & 0.021 & 0.171 \\
\hline & Groups $\times$ Time & 12.630 & 2 & 6.315 & 0.651 & 0.029 \\
\hline & Error & 420.910 & 29 & 14.514 & - & - \\
\hline & Groups & 66.454 & 2 & 33.27 & 0.877 & 0.009 \\
\hline & Error & 7302.291 & 29 & 251.803 & - & - \\
\hline \multirow{5}{*}{$\begin{array}{l}\text { Activity of the } \\
\text { rectos femoris }\end{array}$} & Time & 615.471 & 1 & 615.471 & 0.001 & 0.584 \\
\hline & Groups $\times$ Time & 108.082 & 2 & 54.041 & 0.041 & 0.198 \\
\hline & Error & 438.706 & 29 & 15.128 & - & - \\
\hline & Groups & 106.205 & 2 & 53.102 & 0.774 & 0.018 \\
\hline & Error & 5957.654 & 29 & 205.436 & - & - \\
\hline \multirow{5}{*}{$\begin{array}{l}\text { Strength of the } \\
\text { gluteus maximus }\end{array}$} & Time & 197.659 & 1 & 197.659 & 0.001 & 0.531 \\
\hline & Groups $\times$ Time & 26.629 & 2 & 13.315 & 0.127 & 0.133 \\
\hline & Error & 174.308 & 29 & 6.011 & - & - \\
\hline & Groups & 55.229 & 2 & 27.615 & 0.628 & 0.032 \\
\hline & Error & 1696.708 & 29 & 58.507 & - & - \\
\hline \multirow{5}{*}{$\begin{array}{l}\text { Strength of the ab- } \\
\text { dominal muscles }\end{array}$} & Time & 1467.108 & 1 & 1467.108 & 0.001 & 0.729 \\
\hline & Groups $\times$ Time & 342.526 & 2 & 171.263 & 0.001 & 0.386 \\
\hline & Error & 544.583 & 29 & 18.779 & - & - \\
\hline & Groups & 415.159 & 2 & 207.580 & 0.204 & 0.104 \\
\hline & Error & 3585.950 & 29 & 123.653 & - & - \\
\hline
\end{tabular}


Table 3. Intergroup effects in the pre-test and post-test stages

\begin{tabular}{|c|c|c|c|c|c|}
\hline Variables & Stages & Beta & Standard Error & $\mathbf{t}$ & $\mathbf{P}$ \\
\hline \multirow{3}{*}{ Lordosis degree } & Pre-test & -0.200 & 0.966 & -0.207 & 0.837 \\
\hline & & & & & \\
\hline & Post-test & 5.350 & 1.197 & 4.468 & 0.001 \\
\hline \multirow{2}{*}{$\begin{array}{l}\text { Activity of the gluteus } \\
\text { maximus }\end{array}$} & Pre-test & -0.722 & 3.534 & -0.204 & 0.840 \\
\hline & Post-test & -1.084 & 2.518 & -0.430 & 0.670 \\
\hline \multirow{2}{*}{$\begin{array}{c}\text { Activity of the erector } \\
\text { spinae }\end{array}$} & Pre-test & -1.787 & 2.647 & -0.675 & 0.505 \\
\hline & Post-test & 0.809 & 4.838 & 0.167 & 0.868 \\
\hline \multirow{2}{*}{$\begin{array}{l}\text { Activity of the transverse } \\
\text { abdominis }\end{array}$} & Pre-test & 1.905 & 5.008 & 0.380 & 0.706 \\
\hline & Post-test & 1.618 & 4.873 & 0.332 & 0.742 \\
\hline \multirow{2}{*}{$\begin{array}{l}\text { Activity of the rectos } \\
\text { femoris }\end{array}$} & Pre-test & -4.434 & 3.900 & -1.137 & 0.265 \\
\hline & Post-test & -0.774 & 5.023 & -0.154 & 0.879 \\
\hline \multirow{2}{*}{$\begin{array}{l}\text { Strength of the gluteus } \\
\text { maximus }\end{array}$} & Pre-test & 2.383 & 2.549 & 0.935 & 0.357 \\
\hline & Post-test & 5.551 & 2.309 & 0.346 & 0.732 \\
\hline \multirow{2}{*}{$\begin{array}{l}\text { Strength of the abdominal } \\
\text { muscles }\end{array}$} & Pre-test & 3.717 & 4.017 & 0.925 & 0.363 \\
\hline & Post-test & -6.617 & 3.158 & -2.095 & 0.045 \\
\hline
\end{tabular}

Table 4. Bonferroni post hoc test results for phase effect on the study variables

\begin{tabular}{|c|c|c|c|c|c|c|}
\hline \multirow{2}{*}{ Variables } & \multicolumn{2}{|l|}{ Imagery } & \multicolumn{2}{|l|}{ Active } & \multicolumn{2}{|l|}{ Combined } \\
\hline & Stages & $\mathbf{P}$ & Stages & $\mathbf{P}$ & Stages & $\mathbf{P}$ \\
\hline Lordosis & $\begin{array}{l}\text { Pre-test: } 48.30 \pm 2.21 \\
\text { Post-test: } 46.10 \pm 4.06\end{array}$ & 0.21 & $\begin{array}{l}\text { Pre-test: } 48.40 \pm 2.31 \\
\text { Post-test: } 40.20 \pm 2.39\end{array}$ & 0.001 & $\begin{array}{l}\text { Pre-test: } 48.50 \pm 2.23 \\
\text { Post-test: } 40.75 \pm 2.34\end{array}$ & 0.001 \\
\hline $\begin{array}{c}\text { Activity of the gluteus } \\
\text { maximus }\end{array}$ & $\begin{array}{l}\text { Pre-test: } 79.66 \pm 6.3 \\
\text { Post-test: } 82.78 \pm 4.01\end{array}$ & 0.04 & $\begin{array}{c}\text { Pre-test: } 78.82 \\
\text { Post-test: } 83.34 \pm 6.15\end{array}$ & 0.03 & $\begin{array}{l}\text { Pre-test: } 80.38 \pm 8.01 \\
\text { Post-test: } 83.86 \pm 6.85\end{array}$ & 0.01 \\
\hline $\begin{array}{l}\text { Activity of erector } \\
\text { spinae the }\end{array}$ & $\begin{array}{l}\text { Pre-test: } 82.41 \pm 5.30 \\
\text { Post-test: } 75.33 \pm 11.75\end{array}$ & 0.10 & $\begin{array}{l}\text { Pre-test: } 84.17 \pm 8.55 \\
\text { Post-test: } 77.54 \pm 11.25\end{array}$ & 0.02 & $\begin{array}{l}\text { Pre-test: } 84.20 \pm 4.22 \\
\text { Post-test: } 74.52 \pm 10.95\end{array}$ & 0.001 \\
\hline $\begin{array}{l}\text { Activity of the trans- } \\
\text { verse abdominis }\end{array}$ & $\begin{array}{l}\text { Pre-test: } 79.87 \pm 7.63 \\
\text { Post-test: } 82.63 \pm 11.18\end{array}$ & 0.16 & $\begin{array}{l}\text { Pre-test: } 78.24 \pm 15.21 \\
\text { Post-test: } 79.26 \pm 12.91\end{array}$ & 0.6 & $\begin{array}{l}\text { Pre-test: } 77.96 \pm 10.94 \\
\text { Post-test: } 81.01 \pm 10.13\end{array}$ & 0.02 \\
\hline $\begin{array}{l}\text { Activity of rectos } \\
\text { femoris the }\end{array}$ & $\begin{array}{l}\text { Pre-test: } 75.11 \pm 9.02 \\
\text { Post-test: } 72.33 \pm 12.04\end{array}$ & 0.02 & $\begin{array}{l}\text { Pre-test: } 78.28 \pm 11.14 \\
\text { Post-test: } 68.94 \pm 12.38\end{array}$ & 0.001 & $\begin{array}{l}\text { Pre-test: } 79.54 \pm 7.09 \\
\text { Post-test: } 73.10 \pm 10.88\end{array}$ & 0.01 \\
\hline $\begin{array}{l}\text { Strength of the gluteus } \\
\text { maximus }\end{array}$ & $\begin{array}{l}\text { Pre-test: } 23.80 \pm 5.88 \\
\text { Post-test: } 25.50 \pm 5.58\end{array}$ & 0.07 & $\begin{array}{l}\text { Pre-test: } 19.90 \pm 6.00 \\
\text { Post-test: } 24.70 \pm 4.76\end{array}$ & 0.03 & $\begin{array}{l}\text { Pre-test: } 21.41 \pm 5.96 \\
\text { Post-test: } 25.50 \pm 5.71\end{array}$ & 0.01 \\
\hline $\begin{array}{l}\text { Strength of the ab- } \\
\text { dominal muscles }\end{array}$ & $\begin{array}{l}\text { Pre-test: } 118.30 \pm 11.73 \\
\text { Post-test: } 121.30 \pm 9.14\end{array}$ & 0.11 & $\begin{array}{l}\text { Pre-test: } 109.00 \pm 8.43 \\
\text { Post-test: } 121.50 \pm 6.25\end{array}$ & 0.001 & $\begin{array}{l}\text { Pre-test: } 114.58 \pm 7.82 \\
\text { Post-test: } 127.91 \pm 6.55\end{array}$ & 0.001 \\
\hline
\end{tabular}

$\mathrm{P} \geq 0.05$ indicates no significant difference; $\mathrm{P} \leq 0.05$ indicates a significant difference.

PHYSICAL TREA $\$ MENTS 
Table 5. Bonferroni post hoc test results for group effect on pre-test and post-test on lumbar lordosis degree variables

\begin{tabular}{ccc}
\hline Variables & Groups & $\mathbf{P}$ \\
\hline $\begin{array}{c}\text { Lumbar lordosis } \\
\text { Pre-test }\end{array}$ & Imagery-Active & 0.837 \\
& Imagery - Combined & 0.918 \\
& Active - Combined & 0.872 \\
$\begin{array}{c}\text { Lumbar lordosis } \\
\text { Post-test }\end{array}$ & 0.022 \\
& Imagery-Active & 0.037 \\
\hline Im $\geq 0.05$ indicates no significant difference; $P \leq 0.05$ indicates a significant difference. & 1.00 \\
\hline
\end{tabular}

spinae and rectus femoris muscles $[7,8]$. For this reason, it is used in corrective exercises (Sahrmann exercises) to enhance the gluteus maximus muscle and abdominal muscles, which reduces the erector spinae activity. Also, the exercises used to increase gluteus maximus strength lead to a reduction in the rectus femoris strength [2]. However, there was no significant effect on the activity of the transverse abdominis muscle. Probably because the transverse abdominis muscle is deep and needs more intense and more prolonged training to change its activity rate. Therefore, according to the research objectives, the effect of combined exercise on the EMG activity of the transverse abdominis, gluteus maximus, erector spinae, and rectus femoris muscles was investigated.

The results showed that the combined exercises on increasing the activity of the gluteus maximus and transverse abdominal muscles. There was a significant effect on the decrease of the activity of the rectus femoris and erector spinae muscles because the imaging exercises can alter the rate of muscle activity $[15,22]$, followed up with the active exercise to stabilize the nerve and muscle coordination [15]. Mental practice also increases the activity of the cerebral cortex and increases attention, thus providing better cognitive power. The most important neuromuscular compatibility code, which is cognition, is caused by mental exercise without fatigue, and with active exercises the cognition created is stable $[22,23]$.

The present study also investigated the effect of imagery exercises on the strength of the gluteus and abdominal muscles. Results showed that imagery exercises had no significant effect on the strength of gluteus and abdominal muscles, which was not consistent with the study of Yao et al. Although imagery exercises affected muscle activity rate, it did not affect muscle strength because it was repeated three sessions per week. While in the study of Yao et al., five sessions per week of exercise were found to affect muscle strength [23].
The other objective of our study was to investigate the effect of active exercises on the strength of abdominal muscles. The results showed that active exercises significantly increased the strength of abdominal muscles, which was consistent with the study results of Levine et al. (1997) [24] and Ferreira et al. (2004) [25]. Because by increasing the activity of the abdominal muscles and changing the time of their activation, which plays an essential role in the function of the lumbopelvic structure, we can eliminate the muscle imbalances $[24,25]$. The results also showed that combined exercises had a significant effect on increasing the strength of abdominal muscles. As in the study of Lebon et al. who examined the benefits of mental imagery training on muscle strength, the findings showed that the strength of the leg press was significantly higher in the MVC (maximum voluntary contraction) mental imagery group than the control group [12, 26], because mental training alters the central command of the muscular nervous system. Studies have shown that the brain is activated to produce stronger signals through repeated mental efforts to activate the muscle. As a result, a stronger command in the central nervous system may use inactive motor units, resulting in more force generation $[9,12,26]$. Furthermore, when mental imagery exercises are combined with active exercises, proper neuromuscular coordination is created and as a result, abdominal strength is increased. The present study also aimed to investigate the effect of active exercises on the strength of gluteus maximus muscles. The results showed that active exercises significantly increased the strength of gluteus maximus muscles. The study results were consistent with Alvim et al. and Arab et al. study results $[27,28]$.

As mentioned in these studies, the gluteus maximus muscle plays an essential role in controlling the pelvis and prevents pelvic tilt and subsequent increase in the lumbar hyperlordosis. Therefore, with active exercises, we could induce positive changes in reducing the lumbar 
hyperlordosis by changing the rate of activity and activity pattern of the gluteus maximus. The results showed that combined exercises had a significant effect on increasing the strength of gluteus maximus muscles. The study results were consistent with the study of Kumar et al., who examined imagery exercises on the strength muscle and the gait performance in people with stroke [29]. In this study, strength and performance were improved in the two groups of control (active exercises) and experiments (active and imagery exercises), and there was a significant difference between the two groups [29]. Therefore, studies show that imagery exercises due to physiological and psychological effects can be used as a complementary therapy in rehabilitation and movement pattern modification [29, 30].

Overall, both active and combined exercise methods effectively change the activity of the muscles of the lumbopelvic area. Also, the function of the selected muscles has changed, and more coordination has been established between the selected muscles. As a result, the movement pattern has changed, and more stability has been provided in this area. Based on the results, it reduced the degree of lumbar lordosis in women with lumbar hyperlordosis [1-5].

\section{Conclusion}

The study results showed that combined and active exercises are effective in decreasing the lumbar lordosis and altering the electrical activity of the lumbopelvic muscles. Also, there is no significant difference between the two active and combined methods of exercise. Therefore, it is recommended that in addition to physical training, mental training is used to improve motor patterns in people with functional dysfunction.

\section{Ethical Considerations}

\section{Compliance with ethical guidelines}

The study has a Clinical Trial (Code: (IRCT20130109012078N4) from the Iran Registry of Clinical Trials Center and an Ethics Code (IR.SSRC. REC.1398.073) from the Research Institute of Physical Education and Sports Sciences of University of Tehran.

\section{Funding}

The paper was extracted from the $\mathrm{PhD}$. dissertation of the first author at the Department of Sports Injury and Corrective Exercise, Pardis Alborz of University of Tehran, Tehran.

\section{Authors' contributions}

All authors equally contributed in preparing this article.

\section{Conflict of interest}

The authors declared no conflict of interest.

\section{Reference}

[1] Sahrmann S. Diagnosis and treatment of movement impairment syndromes. Missouri: Mosby; 2002. https://www. google.com/books/edition/Diagnosis_and_Treatment_of_ Movement_Impa/3Z1sAAAAQBAJ?hl $=$ en\&gbpv $=0$

[2] Page P, Frank CC, Lardner R. Assessment and treatment of muscle imbalance: The Janda approach. Champaign: Human kinetics; 2010. http://vlib.kmu.ac.ir/kmu/handle/ $\mathrm{kmu} / 83003$

[3] Kalantari AA, Karimi N, Arab AM, Jaberzadeh S. The effects of active therapeutic exercises on the electromyographic activity of lumbopelvic muscles during prone hip extension in patients with chronic non-specific low back pain. Physical Treatments-Specific Physical Therapy Journal. 2014; 4(3):145-52. http:// ptj.uswr.ac.ir/article-1-198-en.html

[4] Ghamkhar L. [Evaluation of the effect of abdominal maneuvers on the lumbar-pelvic region muscle in patients with chronic low back pain during hip extension (Persian)] [MSc. thesis]. Tehran: University of Welfare and Rehabilitation Sciences; 2010

[5] Sakamoto AC, Teixeira-Salmela LF, de Paula-Goulart FR, de Morais Faria CD, Guimarães CQ. Muscular activation patterns during active prone hip extension exercises. Journal of Electromyography and Kinesiology. 2009; 19(1):105-12. [DOI:10.1016/j.jelekin.2007.07.004] [PMID]

[6] Oh JS, Cynn HS, Won JH, Kwon OY, Yi CH. Effects of performing an abdominal drawing-in maneuver during prone hip extension exercises on hip and back extensor muscle activity and amount of anterior pelvic tilt. Journal of Orthopaedic \& Sports Physical Therapy. 2007; 37(6):320-4. [DOI:10.2519/jospt.2007.2435] [PMID]

[7] Park KN, Cynn HS, Kwon OY, Lee WH, Ha SM, Kim SJ, et al. Effects of the abdominal drawing-in maneuver on muscle activity, pelvic motions, and knee flexion during active prone knee flexion in patients with lumbar extension rotation syndrome. Archives of Physical Medicine and Rehabilitation. 2011; 92(9):1477-83. [DOI:10.1016/j.apmr.2011.03.020] [PMID]

[8] Cornwall MW, Bruscato MP, Barry S. Effect of mental practice on isometric muscular strength. Journal of Orthopaedic \& Sports Physical Therapy. 1991; 13(5):231-4. [DOI:10.2519/ jospt.1991.13.5.231] [PMID]

[9] Ranganathan VK, Siemionow V, Liu JZ, Sahgal V, Yue GH. From mental power to muscle power-gaining strength by using the mind. Neuropsychologia. 2004; 42(7):944-56. [DOI:10.1016/j.neuropsychologia.2003.11.018] [PMID] 
[10] Frenkel MO, Herzig DS, Gebhard F, Mayer J, Becker C, Einsiedel T. Mental practice maintains range of motion despite forearm immobilization: A pilot study in healthy persons. Journal of Rehabilitation Medicine. 2014; 46(3):225-32. [DOI:10.2340/16501977-1263] [PMID]

[11] Guillot A, Lebon F, Rouffet D, Champely S, Doyon J, Collet $\mathrm{C}$. Muscular responses during motor imagery as a function of muscle contraction types. International Journal of Psychophysiology. 2007; 66(1):18-27. [DOI:10.1016/j.ijpsycho.2007.05.009] [PMID]

[12] Gravetter FJ, Forzano LA. Research methods for the behavioral sciences. Boston, MA: Cengage Learning; 2015. https://www.google.com/books/edition/ Research_Methods_for_the_Behavioral_Scie/KzxBAAAQBAJ?hl $=$ en\&gbpv $=0$

[13] Lebon F, Guillot A, Collet C. Increased muscle activation following motor imagery during the rehabilitation of the anterior cruciate ligament. Applied Psychophysiology and Biofeedback. 2012; 37(1):45-51. [DOI:10.1007/s10484-0119175-9] [PMID]

[14] Christakou A, Zervas Y. The effectiveness of imagery on pain, edema, and range of motion in athletes with a grade II ankle sprain. Physical Therapy in Sport. 2007; 8(3):13040. [DOI:10.1016/j.ptsp.2007.03.005]

[15] Hoyek N, Di Rienzo F, Collet C, Hoyek F, Guillot A. The therapeutic role of motor imagery on the functional rehabilitation of a stage II shoulder impingement syndrome. Disability and Rehabilitation. 2014; 36(13):1113-9. [DOI:10. 3109/09638288.2013.833309] [PMID]

[16] Nourbakhsh MR, Arabloo AM, Salavati M. The relationship between pelvic cross syndrome and chronic low back pain. Journal of Back and Musculoskeletal Rehabilitation. 2006; 19(4):119-28. [DOI:10.3233/BMR-2006-19403]

[17] Hojati H. Determine the validity and reliability of the Persian version of motion imagery. [MA. thesis]. Tehran: University of Tehran; 2013.

[18] Youdas JW, Suman VJ, Garrett TR. Reliability of measurements of lumbar spine sagittal mobility obtained with the flexible curve. Journal of Orthopaedic \& Sports Physical Therapy. 1995; 21(1):13-20. [DOI:10.2519/ jospt.1995.21.1.13] [PMID]

[19] Saidi F. [Relation of lumbar pelvic muscles strength with scale of lumbar arch (Persian)] [MA. thesis]. Tehran: University of Tehran; 2007.

[20] Van Tulder MW, Koes BW, Bouter LM. Conservative treatment of acute and chronic nonspecific low back pain: A systematic review of randomized controlled trials of the most common interventions. Spine. 1997; 22(18):2128-56. [PMID] [DOI:10.1097/00007632-199709150-00012]

[21] Williams JG, Odley JL, Callaghan M. Motor imagery boosts proprioceptive neuromuscular facilitation in the attainment and retention of range-of-motion at the hip joint. Journal of Sports Science \& Medicine. 2004; 3(3):1606. [PMID]

[22] Reiser M, Büsch D, Munzert J. Strength gains by motor imagery with different ratios of physical to mental practice. Frontiers in Psychology. 2011; 2:194. [DOI:10.3389/ fpsyg.2011.00194] [PMID] [PMCID]
[23] Yao WX, Ranganathan VK, Allexandre D, Siemionow V Yue GH. Kinesthetic imagery training of forceful muscle contractions increases brain signal and muscle strength. Frontiers in Human Neuroscience. 2013; 7:561. [DOI:10.3389/ fnhum.2013.00561]

[24] Levine D, Walker JR, Tillman LJ. The effect of abdominal muscle strengthening on pelvic tilt and lumbar lordosis. Physiotherapy Theory and Practice. 1997; 13(3):217-26. [DOI:10.3109/09593989709036465]

[25] Ferreira PH, Ferreira ML, Hodges PW. Changes in recruitment of the abdominal muscles in people with low back pain: Ultrasound measurement of muscle activity. Spine. 2004; 29(22):2560-6. [DOI:10.1097/01.brs.0000144410.89182.f9] [PMID]

[26] Lebon F, Collet C, Guillot A. Benefits of motor imagery training on muscle strength. The Journal of Strength \& Conditioning Research. 2010; 24(6):1680-7. [DOI:10.1519/ JSC.0b013e3181d8e936] [PMID]

[27] Alvim FC, Peixoto JG, Vicente EJ, Chagas PS, Fonseca DS [Influences of the extensor portion of the gluteus maximus muscle on pelvic tilt before and after the performance of a fatigue protocol (Portuguese)]. Revista Brasileira de Fisioterapia. 2010; 14(3):206-13. [DOI:10.1590/S141335552010000300002] [PMID]

[28] Massoud Arab A, Reza Nourbakhsh M, Mohammadifar A. The relationship between hamstring length and gluteal muscle strength in individuals with sacroiliac joint dysfunction. Journal of Manual \& Manipulative Therapy. 2011; 19(1): 5-10. [DOI:10.1179/106698110X12804993426848] [PMID] [PMCID]

[29] Kumar VK, Chakrapani M, Kedambadi R. Motor imagery training on muscle strength and gait performance in ambulant stroke subjects-a randomized clinical trial. Journal of Clinical and Diagnostic Research. 2016; 10(3):YC01-4. [DOI:10.7860/JCDR/2016/16254.7358] [PMID] [PMCID]

[30] Dickstein R, Deutsch JE. Motor imagery in physical therapist practice. Physical Therapy. 2007; 87(7):942-53. [DOI:10.2522/ptj.20060331] [PMID] 
Appendix 1.

\begin{tabular}{cc}
\hline Muscles & Electrode Position \\
\hline Gluteus maximus muscle & $1.2-\mathrm{cm}$ distance of $S 2$ to greater trochanter \\
\hline Lumbar erector spinae muscle & $3 \mathrm{~cm}$ apart of $\mathrm{L} 3 \mathrm{Lumbar}$ \\
\hline Transverse abdominis muscle & $2 \mathrm{~cm}$ distal to the upper anterior superior iliac spine to downward and inward \\
\hline Rectus femoris muscle & 1.2 -cm distance of anterior superior iliac spine to under patella \\
\hline
\end{tabular}

PHYSICAL TREA $\$ MENTS

Appendix 2.

Protocol of corrective exercises for the subjects in the active group

Training period: six weeks

Number of practice sessions per week: three

Duration of each training session: 60-75 minutes

Warm-up exercises include walking and stretching movement for five minutes

The main program of exercises was performed for 45 to 60 minutes

Cool down program for five minutes

Corrective Exercises for Lumbar Lordosis

\begin{tabular}{|c|c|}
\hline Exercise number & How to perform the exercises \\
\hline 1 & $\begin{array}{l}\text { Hip and knee extensions: The person lies in a supine position and extends the hip and knee by sliding the heel: it helps to increase } \\
\text { the activation of the abdominal muscles to maintain the position of the pelvis. }\end{array}$ \\
\hline 2 & $\begin{array}{l}\text { Knee flexion in the prone position: The person lies on the prone position and bends the knee, and to prevent anterior pelvic tilt, she } \\
\text { contracts the abdominal muscles, which helps to reduce the activity of the rectus femoris and tensor fascia latae muscles. }\end{array}$ \\
\hline 3 & $\begin{array}{l}\text { Posterior rocking: The person lies in a quadrate limbs position and then tries to fill the lower back with a contraction of the } \\
\text { abdomen, and the spine is in one direction. This exercise increases the activation of the abdominal muscles and decreases the } \\
\text { activity of the lumbar extensor muscles. }\end{array}$ \\
\hline 4 & $\begin{array}{l}\text { Pulsing up in the prone position: The person lies on the prone position and then bends the knee and pulses upwards; this movement } \\
\text { helps to increase the activation of the gluteal muscles. }\end{array}$ \\
\hline 5 & $\begin{array}{l}\text { Hip abduction: Hip abduction in a side position improves pelvic control through the lateral abdominal muscles. When the muscles } \\
\text { of the tensor fascia latae, anterior gluteus medius, and gluteus minimus are short, improving the performance of the posterior } \\
\text { gluteus medius muscle is essential to counteract the activity of these hip flexor muscles. }\end{array}$ \\
\hline 6 & $\begin{array}{l}\text { Femoral extension and shoulder flexion in a quadrate limbs position: The person is placed on a quadrate limb and then tries to } \\
\text { do the opposite femoral extension and flexion of the shoulder. This movement helps to improve abdominal activity and improves } \\
\text { pelvic control, and increases balance. }\end{array}$ \\
\hline 7 & Sitting posture: Correction of sitting posture defects is the most important treatment criterion. \\
\hline 8 & $\begin{array}{l}\text { Standing exercise: Standing and leaning against the wall of the lumbar vertebrae, bend the knees and hips, and contract the } \\
\text { abdominal muscles. This exercise is the best exercise to improve the control of the abdominal muscles while avoiding the activity } \\
\text { of the hip flexor muscles. }\end{array}$ \\
\hline
\end{tabular}

PHYSICAL TREA $\ M E N T S$

Set and number of repetitions of exercises

\begin{tabular}{cccc} 
Week & Set & Repetition & 6 \\
\hline 1 & 1 & 1 & 8 \\
\hline 2 & 2 & 6 & 7 \\
3 & 2 & 2 & 8 \\
5 & 3 & 8 \\
6 & & 3
\end{tabular}

PHYSICAL TREA $\pitchfork$ MENTS 
Protocol of corrective exercises for the subjects in the kinesthetic imagery group

Training period: six weeks

Number of practice sessions per week: three

Duration of each training session: 60-75 minutes

Warm-up exercises include walking and stretching movement for five minutes

The main program of exercises was performed for 45 to 60 minutes

Cool down program for five minutes

It includes corrective exercises in which the person was asked to imagine the exercise in mind and then hold mentally the contraction for 15 seconds and do mentally each exercise 6-8 repetitions like active corrective exercises.

Table of set and number of repetitions of exercises

\begin{tabular}{ccc}
\hline Week & Set & Repetition \\
\hline 1 & 1 & 6 \\
2 & 1 & 8 \\
\hline 3 & 2 & 6 \\
4 & 2 & 7 \\
5 & 2 & 8 \\
6 & 3 & 8 \\
\hline & & PHYSICAL TREATMENTS
\end{tabular}

Protocol of corrective exercises for the subjects in the combined group

Training period: six weeks

Number of practice sessions per week: three

Duration of each training session: 60-75 minutes

Warm-up exercises include walking and stretching movement for five minutes

The main program of exercises was performed for 45 to 60 minutes

Cool down program for five minutes

Combined group exercises include active exercises and kinesthetic imagery that were performed in a blocked form and included active and imagery until the end of the exercise, respectively.

Table of set and number of repetitions of exercises

\begin{tabular}{ccc}
\hline Week & Set & Repetition \\
\hline 1 & 1 & 6 \\
\hline 2 & 1 & 8 \\
\hline 3 & 2 & 6 \\
4 & 2 & 7 \\
\hline 5 & 2 & 8 \\
6 & 3 & 8 \\
\hline
\end{tabular}

PHYSICAL TREA $\ M E N T S$ 